\title{
EEG Profile \& Yield in Evaluation of First Non-febrile Seizures in Children- First Observational Study in Qatar
}

\section{Abdulhafeez M Khair*, Khalid Ibrahim, Rana Alshami, Ahmed Veten, Dalal Elmagrabi and Khalid Mohamed}

Department of paediatrics, Section of Paediatric Neurology, Hamad Medical Corporation, Doha-Qatar

${ }^{*}$ Corresponding author: Abdulhafeez Mohamed Khair. MBBS.CABP.MHPE.MRCPCH. Specialist \& clinical Fellow, Section of Paediatric Neurology, Hamad medical Corporation, P O Box 3050, Doha, Qatar. E-mail: drabboody@hotmail.com

Received date: October 20, 2015; Accepted date: November 26, 2015; Published date: December 04, 2015

Copyright: @2015 Abdulhafeez MK, et al. This is an open-access article distributed under the terms of the Creative Commons Attribution License, which permits unrestricted use, distribution, and reproduction in any medium, provided the original author and source are credited.

\begin{abstract}
Introduction: Seizures are among the most common neurological disorders in the pediatric age group. Up to $10 \%$ of children might experience at least one paroxysmal episode suggestive of seizure activity in their life. It is thought that $5 \%$ of all medical attendances to emergency department are related to seizures. Whether the first nonfebrile seizure is the kick start of long term epilepsy is always a question that physicians and families encounter. Ordering Electroencephalogram (EEG) for children with first non-febrile seizure is a subject of continuous debate.
\end{abstract}

Objectives: To collect demographic background data for children (1 month to 14 years) who presented with the first non-febrile seizure, To determine the prevalence and pattern of EEG abnormalities in Children (1 month to 14 years) with first non-febrile seizure, and To collect possible evidence sufficient to make a recommendation for the use versus abandoning use of routine EEG in children with first episode of non-febrile seizure.

Methods: In a retrospective single-center observational study around (400) children were admitted with first nonfebrile seizure to the Pediatric Emergency Centers (PECs) and their seizure were defined using the international league against epilepsy (ILAE) between January 2012 to December 2013 were studied. EEG was requested for 76 patients. Their EEG were reviewed and interpreted by pediatric neurology consultants. Patients' demographic data and EEG records are then analysed.

Results: Infants unexpectedly represented a small proportion of our cohort. Male gender predominance was noticed. No significant correlation could be found in EEG yield in regard to seizure type. Certain patterns of EEG abnormalities were observed.

Conclusions: Epileptic seizure should be diagnosed clinically and EEG is just a helpful tool. Utility of EEG is debatable in childhood first non-febrile seizure. EEG is helpful but interpretation should be individualized. EEG alone is not very good predictors of seizure recurrence or overall prognosis. Larger scale studies with longer follow up are needed.

Keywords Non-febrile seizure; Electroencephalogram; Epileptiform activity.

\section{Learning points}

This is the first epidemiological study in Qatar in regard to children with epilepsy. It has given almost matching results in regard to background factors \& yield of diagnosis in this small country with unique population constituents. This study however has formed the first step towards establishing paediatric epilepsy database project in Qatar. Recruiting of more patients \& prospective follow up studies are the future visions of this study.

\section{Introduction}

The term seizure is used synonymously with other terminologies including convulsion, fit and epilepsy. A well-known definition is paroxysmal involuntary discharge of cortical neurons that may be manifested clinically by an impairment or loss of consciousness, abnormal motor activity, behavioral and emotional disturbances, sensory abnormalities or autonomic dysfunction [1]. Differentiating an epileptic seizure from a non-epileptic paroxysm is not an easy clinical judgment in all times, especially among pediatric population. Nevertheless, diagnosis of epileptic seizure is almost always clinical and other diagnostic tools only often add a little to accuracy of diagnosis.

Exact epidemiology of childhood first unprovoked seizures is largely unknown precisely. Every year up to 40,000 children experience their first afebrile seizure in the United States [2]. Overall life risk of developing epilepsy varies a lot among available literature and may range from $0.5 \%$ to up to $10 \%$ [3-5]. We know that such statistics do vary depending on the geography, age, background history, existence of other medical abnormalities and distribution among certain patients' populations. It is estimated that approximately 1 billion dollar is spent annually on pre-hospital and emergency seizure care in the United States [6].

Risk of seizure recurrence after the first non-febrile seizure also varies among different studies. $40-80 \%$ of children with their first nonfebrile seizure will may develop a second seizure regardless of what 
sort of evaluation they are exposed to [7- 9]. Predictors of such recurrence might include child age, seizure details, patient and family history, presence of medical co-morbidities, neuro-imaging pathology and certain EEG abnormalities [9].

Having an EEG record after the first non-febrile seizure is not an internationally agreed practice. Yield of EEG in such circumstances is always questionable especially it is usually done post-ictally. There is no data in the whole Arabic gulf area with its special population that elaborate on this practice \& its usefulness. It seems it is often a personal decision depending on practice \& experience when doing such test. Moreover, national and institutional recommendations are obviously lacking in this part of the world.

\section{Methods and Results}

In a retrospective observational study 76 children who were admitted with first afebrile seizure in emergency center of pediatric and their seizure were defined using the international league against epilepsy (ILAE) and they underwent EEG recording between January 2012 to December 2013 were studied. All their data were reviewed and analysed.

Inclusion criteria: children age (1month-14 years) with first afebrile seizure previously healthy. Children who presented with first afebrile convulsive status epilepticus also were included.

Exclusion criteria: children presenting with febrile convulsion and children with a known underlying genetic and metabolic disorder have been excluded. Those who are not subjected to EEG testing and reporting have been excluded as well.

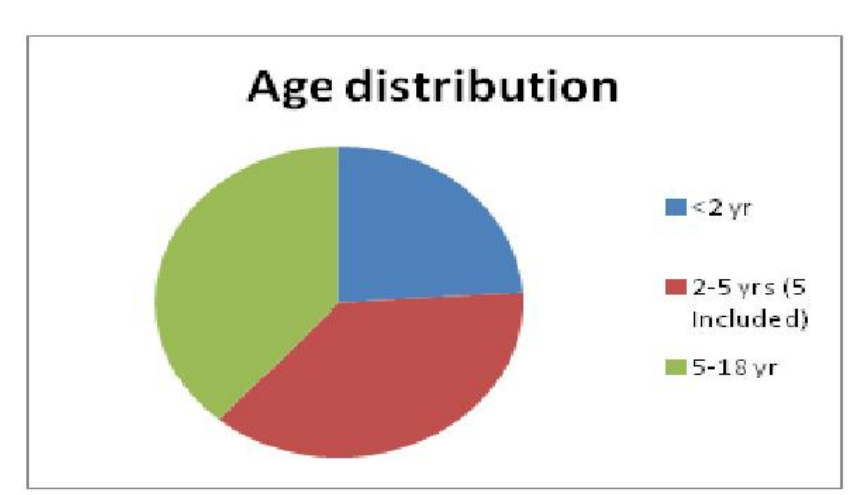

Chart 1: Age distribution: Is shown in the following chart

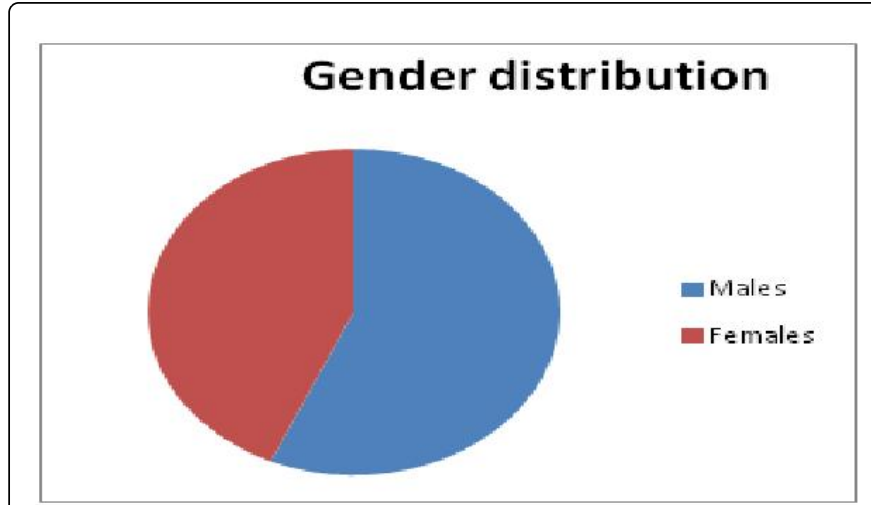

Chart 2: Gender distribution: Is shown in the following chart

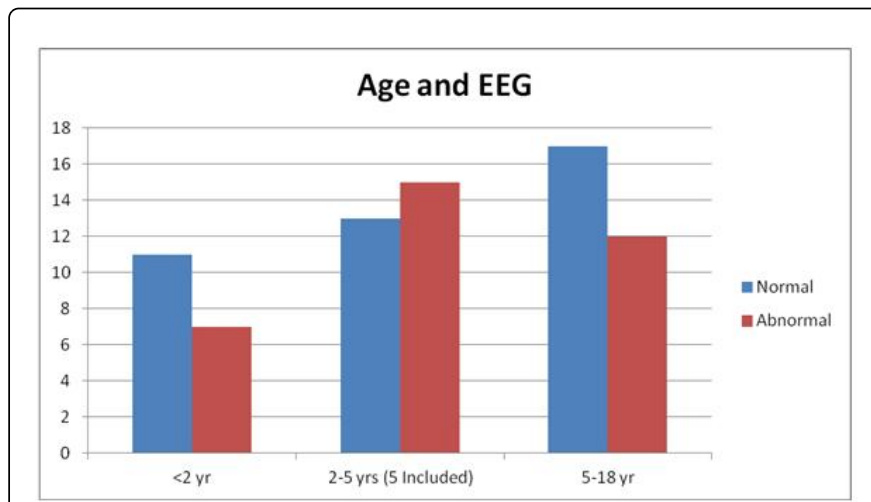

Chart 3: EEG yield in regard to age: Is shown in the following chart

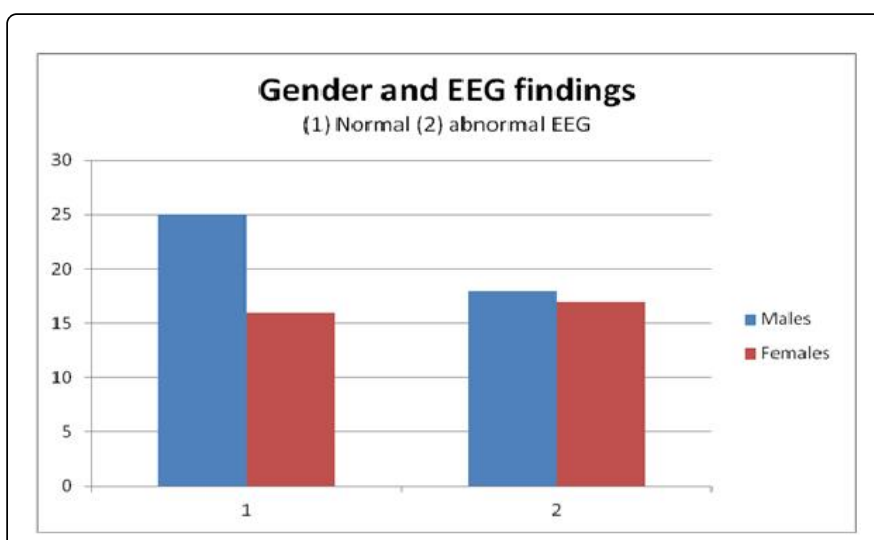

Chart 4: EEG yield in regard to gender: Is shown in the following chart 
Page 3 of 5

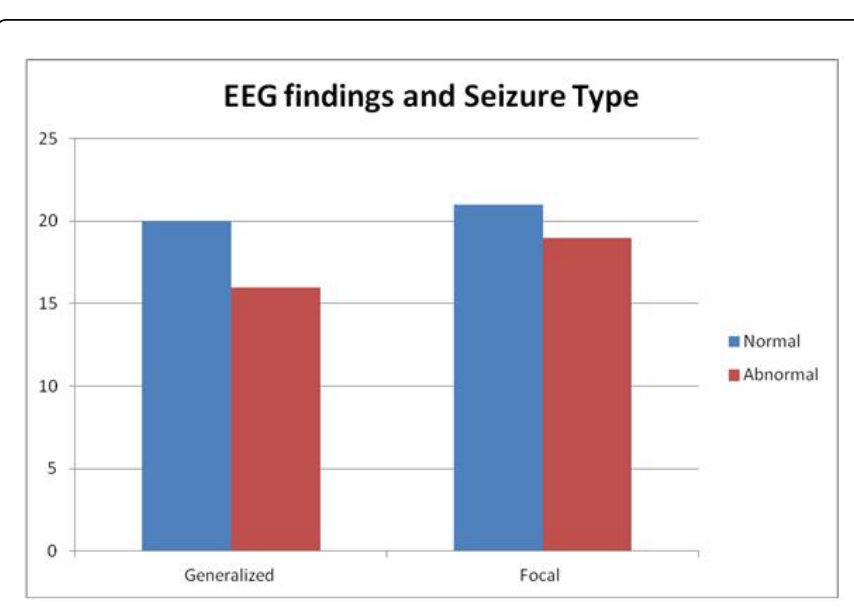

Chart 5: EEG yield in regard to seizure semiology: Is shown in the following chart

\begin{tabular}{|l|l|l|l|l|l|l|}
\hline & No & $\%$ & $\begin{array}{l}\text { Normal } \\
\text { EEG }\end{array}$ & $\%$ & $\begin{array}{l}\text { Abnormal } \\
\text { EEG }\end{array}$ & $\%$ \\
\hline Males & 43 & $56.58 \%$ & 25 & $58.14 \%$ & 18 & $41.86 \%$ \\
\hline Females & 33 & $43.42 \%$ & 16 & $48.48 \%$ & 17 & $51.52 \%$ \\
\hline$<2$ yrs & 18 & $23.68 \%$ & 11 & $61.11 \%$ & 7 & $38.89 \%$ \\
\hline $2-5$ yrs & 28 & $36.84 \%$ & 13 & $46.43 \%$ & 15 & $53.57 \%$ \\
\hline$>5-14$ yrs & 29 & $38.16 \%$ & 17 & $58.62 \%$ & 12 & $41.38 \%$ \\
\hline $\begin{array}{l}\text { Generalize } \\
\text { d }\end{array}$ & 36 & $46.37 \%$ & 20 & $55.56 \%$ & 16 & $44.44 \%$ \\
\hline Focal & 40 & $52.63 \%$ & 21 & $52.50 \%$ & 19 & $47.50 \%$ \\
\hline
\end{tabular}

Table 1: Summary of demographic data and EEG yield: Is shown in the following table

\begin{tabular}{|l|c|}
\hline EEG abnormality & No of patients \\
\hline Temporal sharp wave discharges & 7 \\
\hline Centero-temporal spikes & 6 \\
\hline Occipital spikes/spike-waves & 6 \\
\hline Generalized slowing & 4 \\
\hline Focal slowing & 3 \\
\hline Frontal sharp wave discharges & 1 \\
\hline 3Hrz/s spike \& wave activity & 1 \\
\hline Central epileptic discharges & 1 \\
\hline Generalized high spike/waves & 1 \\
\hline Fronto-temporal sharp waves & 1 \\
\hline Runs of sharp delta & 3 \\
\hline
\end{tabular}

Table 2: EEG abnormalities: Showing list of EEG abnormalities. Total number of patients is 35 .

\section{Discussion}

First unprovoked seizures are likely to happen more in the extremes of ages [10-12]. In our study however, less than one fourth of the patients had their first unprovoked seizure before the age of two years (Chart 1, Chart 3, Table 1). Possible expansion of our moderate size population might have observed more patients within those age groups. Moreover, recognition of the first seizure in the very young age group might be quite challenging for both families and physicians.

In our study we have observed some male predominance $(57 \%$ versus $43 \%$ ) among our pediatric population patients (Chart 2, Chart 4, Table 1). This was consistent with international data which have shown the same male gender predominance $[10,13]$. The reason behind such observation is not ready clear. It is known that some genetic epilepsy syndromes are more prevalent among males, but this observation can't uncover the full precise science behind such prevalence completely. Nevertheless, obviously other hidden hormonal and genetic factors do play a role as well [14].

We have tried to match the yield of EEG against the type of seizure. In our study we have not noticed any significant difference between percentages of normal versus abnormal EEG in regard to the seizure type, whether focal or generalized (Chart 5)(Table1). This is consistent with current literature observation as well [15-16]. In spite of minimal significance, physicians still tend to obtain EEG more readily after the first focal seizure more than the generalized one, probably trying to localize any possible electrical foci.

We have reviewed the EEG abnormalities in our study group (Table 2). Most of abnormalities were in the form of focal discharges confined to a specific brain lobe (22 out of 35 patients). Focal slowing was reported in 4 patients whereas generalized non-specific slowing was observed in another 4 patients. These figures are in harmony with observation in literature [15-16]. We have recorded 6 patients with classical centero-temporal spikes suggestive of benign epilepsy of childhood with centero-temporal spikes (BECTS) and one patient with $3 \mathrm{~Hz} / \mathrm{s}$ spike and wave suggestive of childhood absence epilepsy. This might show the power of early EEG in helping diagnosing possible underlying epilepsy syndrome.

\section{Literature Review}

In general we have observed that literature originating from USA tend to recommend obtaining an EEG in every child presenting with the first non-febrile unprovoked seizure [17]. EEG epileptiform abnormalities might be detected in up to $59 \%$ of children with first non-febrile seizure [18]. EEG utility varies according to clinical indication though. It can help detecting subtle focality in the presence of normal MRI [19]. It can also aids in the diagnosis of some special epilepsy syndromes [19]. Estimation of recurrence risk depending on EEG record is been studied as well with variable outcomes [18-19].

Timing of obtaining the EEG after the first seizure is rather complex technically and logistically. Some experts recommend obtaining EEG after 24-48 hour after occurrence of the seizure, though that might not be all the time feasible. Transient post-ictal slowing is seen often after a real epileptic seizure; however it is a poorly-specific finding. In the other way around, in patients where the diagnosis of epileptic event is doubtful it may help supporting the diagnosis of epileptic seizure. Such EEG study should include awake and a sleep records with application of augmenting procedures such as photic stimulation \& hyperventilation as possible $[17-18,20]$. These procedures are meant to 
increase the yield of EEG to the maximal possible. Having the cooperation as an issue in children, so obtaining a full study record might not be doable at all times. Not all health facilities have EEG available for arrangement straight away. Thus following such timing recommendations is often governed by the overall facility level \& structure.

Studies have tried to elaborate on the best set up to do EEG for children with first non-febrile seizure. Although obtaining a fast EEG might be recommended, at present there is no evidence having EEG in the emergency department has increase such yield [21-22]. Arranging for outpatient EEG testing appears to be the most optimal clinical practice. The sooner EEG is obtained the better as experts' do advice in general. Medical professionals however should bear in mind that abnormal EEG does not diagnose epilepsy in its own; neither normal EEG can be used as an accurate screening tool.

Often the initial EEG is normal but the clinical suspicion is rather high. Following the clinical judgment is then recommended. Sleep deprived EEG is a useful tool in such circumstances. Different institutions have different protocols for EEG sleep deprivation plans. Most of them, however, involve late sleep, early awakening concept. Some centers tend to use melatonin as a sleeping aid. Sleep deprived EEG might detect up to one third of patients with initial normal EEG, given that it is done within few days [18].

Prognostic utility of EEG is another complex task for medical professionals. Most of studies that have addressed the prognostic values of EEG for children with first non-febrile seizure are rather old studies. At least four studies have used focal slowing \& epileptiform electrical discharges as predictors of seizure recurrence [23-26]. It is now well known that focal slowing can be transient post-ictal phenomena \& interpretation of such record should be done with extreme caution. In the absence of any other pathology, one study has concluded that one half of children who had abnormal EEG after their first unprovoked non-febrile seizure had a later recurrence. This was compared to one fourth of children who had normal EEG in the same study [24].

A relevant issue has been raised by the famous Dr Panayiotopolous from St. Thomas's Hospital and his group in the sense of pushing a step ahead towards obtaining EEG in all children with first non-febrile seizure [27]. In his study, Dr Panayiotopolous has made a point that diagnosis of a specific epileptic syndrome is a big advantage of having an early EEG after the first seizure. He had defined the advantages of an EEG after the first seizure, 'stating that the child and the family are entitled to a diagnosis, prognosis and management that is specific and precise, even though this may only be possible in a select-proportion of patients after the first seizure' [27].

In spite of all mentioned studies, agreement of obtaining EEG after the first unprovoked seizure is not really universal. Camfield and his group have commenced anti-epileptic medications based on the initial EEG reading with disappointing ultimate outcomes [23]. Percentage of seizure recurrence in the treated \& non-treated groups was statistically insignificant. Having epileptiform activity as a predictor of seizure recurrence had shown a sensitivity of only 0.55 . It is worth mentioning that EEG recording results had included both neurologically normal impaired children without separation [23].

Stroink and his group had done something different [25]. In this Dutch study no child was treated after the first seizure \& patients were rather followed up. Overall recurrence at two years follow up was $54 \%$ [25]. The study had calculated a pretest probability based on a lot of clinical factors. The study had concluded that EEG was not useful when the pretest probability of recurrence is less than 0.66 , because even if it was abnormal, as the child's risk of recurrence did not exceed the treatment threshold, set at $80 \%$ recurrence risk [25].

Tron and his study group from France had reported around same figures [28]. The seizure recurrence in his 100 children population (all were healthy before) was 0.32 . The recurrence risk in those who had epileptiform activity in EEG was 0.42 compared to 0.28 in those with normal EEG (28). The difference was not found to be statistically significant $(\mathrm{P}=0.14)$.

In this era, Shinnar and his group probably had conducted the largest study in the previous decade involving more than 400 children (29). Seizures in this study were divided into two groups cryptogenic and remote symptomatic based on their clinical assessment. In this study usefulness of EEG was almost none in the remote symptomatic group with less than $5 \%$ difference in the recurrence rates between those with normal and abnormal EEG records [29]. Overall recurrence rate was $52 \%$ at 2 years follow up [29].

Another argument in favour of not asking for EEG after the first seizure was raised by Dr Richard Appleton, a pediatric neurologist from the UK. He had claimed that EEG is a costly and unhandy procedure in most health care facilities excluding tertiary centers [30]. $\mathrm{He}$ also put a point that if the clinical decision was to wait without treatment after the first seizure due to low recurrence rates, EEG would have been pointless [30].

A major continuous concern regarding EEG reading is the extreme subjectivity. EEG is often read with different categories of medical professionals with variable background, training, and understanding of brain maturation and level of expertise. Tan et al had raised this concern in his recent paper soon National Institute of Clinical Excellence (NICE) 2004 guidelines had been launched with the same argument [31].

A more recent yet large study by Gilbert et al and his group with almost 10 years follow up prospective study had also argued against routine use of EEG [32]. This study had showed that the likelihood of making a clinically useful diagnosis by performing an EEG in every child after first seizure was low [32]. Based on its poor information outcome, this study had concluded that EEG should be ordered very individually rather than routinely in children with first non-febrile seizure [32].

\section{Conclusion}

Epilepsy remains a clinical diagnosis, thus obtaining an accurate history is a mandate. This should include elaborating on medical background, developmental history, family history, context of the seizure, detailed description of the ictal and post-ictal events, and thorough physical examination. EEG is not meant to be used as a white versus black tool in diagnosing or ruling out epileptic episodes. EEG however can be very useful aid in the clinical evaluation. It can help in identifying background function, epilptiform focality, need for further tests and neuro-imaging, directing further investigation, diagnosis some epilepsy syndromes, rough estimation of recurrence chances and discussion on further counselling and prognosis. Nevertheless, EEG should be read with the best available trained professionals paying attention to transient and maturational changes.

There is still an unsolved scientific debate in regard to ordering EEG after the first non-febrile seizure and available literature haven not yet 
unravel of this obscured area. Our study in Qatar has shown comparable figures as far as patients' age distribution, background, seizure semiology, and pattern of EEG recording results. However our preliminary experience needs a longer follow up in order to drag out any possible institutional conclusions and final guidelines.

\section{Recommendations}

Obtaining EEG after the first unprovoked afebrile seizures in children is not routinely recommended according to our study. EEG however can be useful with higher yield with presence of certain risk factors or when a specific epilepsy syndrome is suspected. Thus it is important to review every case individually \& keep such testing under consideration accordingly. Follow up of patients enrolled in this study prospectively might yield more precise results especially in terms of prediction of future seizures. Large scale studies are obviously needed, especially in this part of the world where patients' demographics and clinical presentations might be rather unique.

\section{Funding}

Medical Research Center-Hamad Medical Corporation

\section{References}

1. Rober H A Haslam (1997) Pediatrics in Review 18: 39-49.

2. Kaufman L, Hesdorffer D, Mu Kherjee R, Hauser WA (1996) Incidence of first unprovoked seizures among children in Washington Heights, New York City, 1990-1994. Epilepsia 37: 85

3. Russ SA, Larson K, Halfon N (2012) A national profile of childhood epilepsy and seizure disorder. Pediatrics 129: 256-264.

4. Oka E, Ohtsuka Y, Yoshinaga H, Murakami N, Kobayashi K, et al. (2006) Prevalence of childhood epilepsy and distribution of epileptic syndromes: a population-based survey in Okayama, Japan. Epilepsia 47: 626-630.

5. Johnston MV (2004) Seizures in Childhood: Nelson textbook of pediatrics (17thedn), W.B. Saunders Company, Philadelphia, London 1993-2005.

6. Martindale JL, Goldstein JN, Pallin DJ (2011) Emergency department seizure epidemiology. Emerg Med Clin North Am 29: 15-27.

7. Chan D, Phuah HK, Ng YL, Choong CT, Lim KW, et al. (2010) Pediatric epilepsy and first afebrile seizure in singapore: Epidemiology and investigation yield at presentation. Journal of Child Neurology 25: 1216-1222

8. Daoud AS, Ajloni S, El-Salem K, Horani K, Otoom S, et al. (2004) Risk of seizure recurrence after a first unprovoked seizure: a prospective study among Jordanian children. Seizure 13: 99-103.

9. Ramos Lizana J, Cassinello Garciá E, Carrasco Marina LL, Vázquez López M, Martín González M, et al. (2000) Seizure recurrence after a first unprovoked seizure in childhood: a prospective study. Epilepsia 41:1005-1013.

10. Hauser WA, Annegers JF, Kurland LT (1993) Incidence of epilepsy and unprovoked seizures in Rochester, Minnesota: 1935-1984. Epilepsia 34: 453-468.

11. Kotsopoulos I, de Krom M, Kessels F, Lodder J, Troost J, et al. (2005) Incidence of epilepsy and predictive factors of epileptic and non-epileptic seizures. Seizure 14: 175-182.
12. Duggan MB (2010) Epilepsy in rural Ugandan children: seizure pattern, age of onset and associated findings. Afr Health Sci 10: 218-225.

13. Hauser WA, Beghi E (2008) First seizure definitions and worldwide incidence and mortality. Epilepsia 49 Suppl 1: 8-12.

14. McHugh JC, Delanty N (2008) Epidemiology and classification of epilepsy: gender comparisons. Int Rev Neurobiol 83: 11-26.

15. Seneviratne U, Cook M, D'Souza W (2011) The electroencephalogram of idiopathic generalized epilepsy. Epilepsia 53: 234-48.

16. Dusitanond P (2013) Abnormal electroencephalography in first unprovoked seizure in Rajavithi Hospital. J Med Assoc Thai 96 Suppl 3: S42-46.

17. Hirtz D, Ashwal S, Berg A, Bettis D, Camfield C, et al. (2000) Practice parameter: evaluating a first nonfebrile seizure in children: report of the quality standards subcommittee of the American Academy of Neurology, The Child Neurology Society, and The American Epilepsy Society. Neurology 55: 616-623.

18. King MA, Newton MR, Jackson GD, Fitt GJ, Mitchell LA, et al. (1998) Epileptology of the firs-seizure presentation: a clinical electroencephalographic and magnetic resonance imaging study of 300 consecutive patients. Lancet. 352:1007-1011.

19. Pohlmann-Eden B, Newton M (2008) First seizure: EEG and neuroimaging following an epileptic seizure. Epilepsia 49 Suppl 1: 19-25.

20. Berg AT (2008) Risk of recurrence after a first unprovoked seizure. Epilepsia 49 Suppl 1: 13-18.

21. Vining EP, Freeman JM (1986) Management of nonfebrile seizures. Pediatr Rev 8: 185-190.

22. Holmes GL (1988) How to evaluate the patient after a first seizure. Postgrad Med 83: 199-209.

23. Camfield PR, Camfield CS, Dooley JM, Tibbles JA, Fung T, et al. (1985) Epilepsy after a first unprovoked seizure in childhood. Neurology 35: 1657-1660.

24. Shinnar S, Kang H, Berg AT, Goldensohn ES, Hauser WA, et al. (1994) EEG abnormalities in children with a first unprovoked seizure. Epilepsia 35: 471-476.

25. Stroink H, Brouwer OF, Arts WF, Geerts AT, Peters ABC, et al. (1998) The first unprovoked, untreated seizure in childhood: a hospital based study of the accuracy of diagnosis, rate of recurrence, and long term outcome after recurrence. Dutch study of epilepsy in childhood. J Neurol Neurosurg Psychiatry. 64: 595-600.

26. Martinovic Z, Jovic N (1997) Seizure recurrence after a first generalized tonic-clonic seizure, in children, adolescents and young adults. Seizure 6: 461-465.

27. Panayiotopoulos CP (1998) Significance of the EEG after the first afebrile seizure. Arch Dis Child 78: 575-576.

28. Boulloche J, Leloup P, Mallet E, Parain D, Tron P (1989) Risk of recurrence after a single, unprovoked, generalized tonic-clonic seizure. Dev Med Child Neurol 31: 626-632.

29. Shinnar S, Berg AT, Moshe SL, O'Dell C, Alemany M, et al. (1996) The risk of seizure recurrence after a first unprovoked afebrile seizure in childhood: an extended follow-up. Pediatrics 98: 216-225.

30. Appleton RE (1999) Significance of the EEG after the first afebrile seizure. Arch Dis Child 80: 100-101.

31. Tan M, Appleton R, Tedman B (2008) Paediatric EEGs: what NICE didn't say. Arch Dis Child 93: 366-368.

32. Gilbert DL, Buncher CR (2000) An EEG should not be obtained routinely after first unprovoked seizure in childhood. Neurology 54: 635-641. 